\title{
Clinical \& Microbiological profile of Fournier's Gangrene in a Tertiary Care Hospital in Bangladesh : A prospective observational study
}

\author{
Tapash Kumar Maitra ${ }^{1}$, Mahmud Ekramullah², Nilufar Shabnam³, Sharmistha Roy ${ }^{4}$, Samiran Kumar Mondol ${ }^{5}$
}

\begin{abstract}
Background: Fournier's gangrene is the necrotising fasciitis of the genitalia and perineum, with associated poly microbial infection. Evidence based data in the very recent years suggest that it is associated with significant and potential risk of organ failure or death.

Aim: This study was designed to be conducted among the patients suffering from Fournier's gangrene with a view to assess the probable prevalence rate of potentially adverse clinical consequences during course of treatment, overall mortality and to observe the microbiological pattern in our surgical practice.

Method \& materials: This cross sectional study was conducted among the 69 patients of Fournier's gangrene in BIRDEM General Hospital, Dhaka, Bangladesh from Jan 10.2013 to Sept 01 .2016, using the purposive sampling method.

Results: The results of this study reflects that majority (43.4\%) of the study population were in 51 to 60 years age group (Mean age $43 \pm 1.7$ years) in study population. By using the Laboratory Risk Indicator for Necrotizing Fasciitis (LRINEC) score, it was found that in most of the patients (approx 56.5\%), a suspicious score ranging 06-08 was observed and only in $10.1 \%$ patients, a specific score of $\geq 08$ was observed. In $27.5 \%$ patients systemic complications like DIC, ARDS, MODS, MSOF and severe sepsis were observed in 1.4\%, 4.3\%, 10.1\%, 4.3\% and 5.7\% cases respectively. Mortality rate was approximately $4.3 \%$. Majority (84.1\%) of the patients were associated with type 1 (Polymicrobial) bacterial infection, whereas in case of $15.9 \%$ patients, it was associated with type 2 (Monomicrobial) infection. Escherichia coli was the most frequently observed micro-organisms associated with approximately $39.1 \%$ of all cases. S. aureus, Staphylococcus pyogenes, Enterococci species, E.coli and Pseudomonas species were recorded to be associated with $17.4 \%, 27.5 \%, 21.7 \%, 39.1$ and $10.1 \%$ cases respectively.
\end{abstract}

Conclusion: This study suggests that Fournier's gangrene is associated with significant systemic complications. Poly microbial infections are most predominant and E coli infection was commonest organism involved.

Keywords: Fournier's gangrene, sepsis, microbial profile.

\section{Introduction:}

Fournier's gangrene is an uncommon, rapidly progressive infection of the male external genital, perineal and perianal regions with occasional cranial extension to the abdominal wall. It is characterized by a synergistic, necrotizing fasciitis (NF) leading to the thrombotic occlusion of small subcutaneous vessels and the development of gangrene ${ }^{1}$.

1. Dr. Tapash Kumar Maitra, Associate Professor \& Head of the Dept., Department of Surgery, BIRDEM General Hospital, Bangladesh.

2. Dr. Mahmud Ekramullah, Assistant Professor, Department of Surgery, BIRDEM General Hospital, Bangladesh.

3. Dr. Nilufar Shabnam, Registrar, Department of Surgery, BIRDEM General Hospital, Bangladesh.

4. Dr. Sharmistha Roy, Assistant Professor, Department of Surgery, BIRDEM General Hospital, Bangladesh.

5. Dr. Samiran Kumar Mondol, Associate Professor, Department of Surgery, BIRDEM General Hospital, Bangladesh.

\section{Corresponding Author:}

Dr. Tapash Kumar Maitra

Associate Professor \& Head of the Dept.

Department of Surgery, BIRDEM General Hospital

Dhaka, Bangladesh

Email: tapashkm1965@gmail.com
There are two types of Fournier's gangrene such as Type I and II ${ }^{2,3}$. The majority of patients with Fournier's gangrene are immunocompromised and thus the primary wound might have been minor or might have arisen from an otherwise uneventful surgery ${ }^{3,4}$. Diabetes mellitus, malignant disease, obesity, peripheral vascular disease, local trauma, urethral stricture and perianal disease have been cited as the main predisposing factors ${ }^{5}$. Early diagnosis, supportive measures and the use of broad-spectrum antibiotics with prompt and aggressive surgical debridement remain the cornerstone of management ${ }^{6}$. In spite of recent advancements in management, mortality is still high and averages 20-30 percent ${ }^{4}$.

NF is a rapidly spreading, inflammatory infection of the deep fascia, associated with secondary necrotic changes of subcutaneous tissue ${ }^{7}$. It is perhaps the most aggressive form of necrotizing soft tissue infection ${ }^{8}$ and can spread rapidly to entire limb within hours 9 . The first description of NF was given in the fifth century B.C by Hippocrates ${ }^{10}$. In 1921, Wilson coined the term "NF" which aptly describes its pathologic process ${ }^{11}$. Many other terminologies are used to describe same disease process such as Fournier's gangrene (perineum), phagedena gangrene, bacterial synergistic gangrene, and Meleney's gangrene (abdominal wall) ${ }^{12}$. 
At the initial stages of presentation, it has a paucity of clinical signs and is difficult to differentiate it from cellulitis. A high index of suspicion is needed to diagnose it. According to the microbiological characteristics, NF is classified into Type 1 (synergistic polymicrobial infections including anaerobes) and Type 2 (mono microbial infections), the former being more common ${ }^{13.14}$. The most common mono microbial infection causing organisms include Beta-hemolytic Streptococcus, Staphylococcus aureus, and Clostridial species. Common poly microbial synergistic infection causing organisms includes $S$. aureus, Staphylococcus pyogenes, Enterococci species, Escherichia coli, Pseudomonas species, and anaerobic organisms such as Bacteroides $^{15,16}$.

The precise pathogenesis of Fournier's gangrene is unclear. Inoculation of microbes can occur through minor trauma, snake or insect bite, surgical incisions, etc. Under favorable environmental conditions such as immune compromised states, diabetes mellitus, liver failure and renal failure, organisms multiply to cause disease process etc. ${ }^{17,18}$. The process of NF in first starts in deep tissue plane, so superficial skin signs may not be evident initially. This usually leads to a delayed diagnosis of this condition. Many patients present with toxic features due to sepsis without any/minimal underlying signs. Later, they may develop edema, tenderness, vesicle, bullae, and crepitus ${ }^{17,19}$.

NF in general is usually diagnosed by clinical features, but other investigations may help to confirm it. Plain X-ray may show subcutaneous gas. Computed tomography scan and magnetic resonance image may show asymmetrical fascial thickening, fat stranding, and gas tracking along fascial planes $^{18}$. Tissue biopsy reveals necrosis, polymorph nuclear infiltration and thrombosis of vessels. The management includes initial resuscitation, supportive care, adequate control of risk factors such as blood sugars; extensive debridement which may have to be repeated, intravenous antibiotics, and occasionally radical procedures such as amputations ${ }^{17}$.

The mortality rates of NF have remained alarmingly high with reported mortality rates ranging from $20 \%$ to $30 \%{ }^{18}$. Multiple studies have shown that delay in the diagnosis and consequently delayed operative debridement which has caused increase in the mortality ${ }^{19}$. The purpose of this study is to look at Fournier's gangrene in terms of its clinical consequences and microbiological characteristics.

\section{Materials and Methods:}

This was as a cross sectional study among the 69 patients of Fournier's gangrene at BIRDEM General Hospital, Dhaka, Bangladesh from a period between Jan 10.2013 and Sept 09.2016 with aim of assessing the infectious profile, microbiology pattern and clinical complications. Study subjects were between 20 to 70 years of age.

Purposive sampling was used as the sampling technique. Data was processed, presented in tabulated form and discussed with compare \& comparison on the basis of statistical analysis. In this study, Laboratory Risk Indicator for
Necrotizing Fasciitis (LRINEC) score is used among the study population ${ }^{20}$ (Figure I).

\section{Variable, Units}

Score

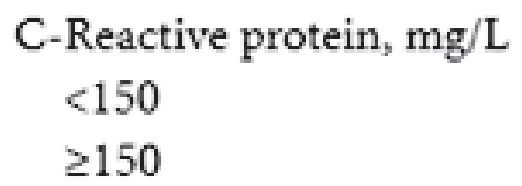

Total white cell count, per $\mathrm{mm}^{3}$ $<15$

15-25

$>25$

Haemoglobin, g/dL

$>13.5$

11-13.5

$<11$

Sodium, $\mathrm{mmol} / \mathrm{L}$

$\geq 135$

$<135$

Creatanine, $\mu \mathrm{mol} / \mathrm{L}$

$\leq 141$

$>141$

Glucose, $\mathrm{mmol} / \mathrm{L}$

$\leq 10$

$>10$

Figure I:

\section{Results}

Among the 69 study subjects, the age distribution is shown in Table 1.

Table 1:

\begin{tabular}{lcc}
\hline Age in years & $\boldsymbol{n}=\mathbf{6 9}$ & $\boldsymbol{\%}$ \\
\hline $20-30$ & 03 & 4.3 \\
$31-40$ & 04 & 5.8 \\
$41-50$ & 13 & 18.8 \\
$51-60$ & 30 & 43.4 \\
$61-70$ & 19 & 27.5 \\
Total & 69 & 100 \\
Mean \pm SD & $\mathbf{4 3 \pm 1 . 7}$ & \\
\hline
\end{tabular}


Following admission all patients were assessed by LRINEC score, the results of which are shown in Table 2. Adverse complications in course of treatment are in Table 3. Microbiological type of Fournier's gangrene is represented in Figure 1.

Table 2:

\begin{tabular}{lccc}
\hline Score & Interpretation & No. of case & \% \\
\hline$\geq 08$ & Specific & 07 & 10.1 \\
$06-08$ & Suspicion & 39 & 56.5 \\
$03-05$ & Less specific & 17 & 24.6 \\
$<03$ & Non-specific & 06 & 8.7 \\
Total & & 69 & 100
\end{tabular}

Table 3:

\begin{tabular}{lcc}
\hline Complications & Cases & \% \\
\hline Systemic manifestation & 19 & 27.5 \\
$\begin{array}{l}\text { DIC(Disseminated Intra } \\
\text { Vascular Coagulation) }\end{array}$ & 01 & 1.4 \\
$\begin{array}{l}\text { ARDS (Acute Respiratory } \\
\text { Distress Syndrome) }\end{array}$ & 03 & 4.3 \\
$\begin{array}{l}\text { MODS(Multiple Organ } \\
\text { Dysfunction Syndrome) }\end{array}$ & 07 & 10.1 \\
$\begin{array}{l}\text { MSOF (Muli System } \\
\text { Organ Failure) }\end{array}$ & 03 & 4.3 \\
Severe sepsis & 04 & 5.7 \\
Death & 03 & 4.3 \\
\hline
\end{tabular}

We have observed that $84.10 \%$ cases and $15.90 \%$ cases among our study subjects were Type I (Poly microbial ) and Type II (Mono microbial) respectively.

Predominant micro-organisms based on culture sensitivity of pus and tissues of cases are shown in Figure 2.

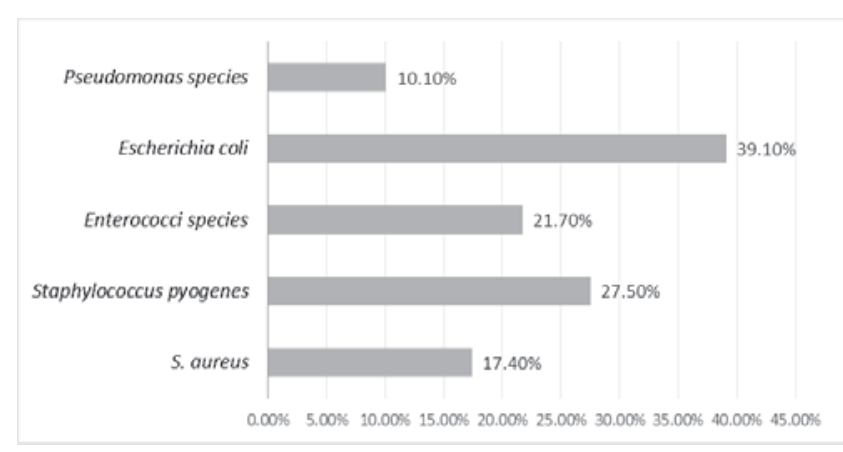

Figure 2:

\section{Discussion:}

In our study majority (43.4\%) of the study population were in 51 to 60 years age group followed by $27.5 \%$ who were in 61 to 70 years age group. In a study by Wong $\mathrm{CH}$ and Wang YS who studied 30 patients with Fournier's gangrene ${ }^{21}$ and observed that, mean age of occurrence was 48 years, who were predominantly male farmers. The age range varied between 22 years and 84 years. There were 28 males $(93.3 \%)$ and only 2 females $(6.7 \%)$.

LRINEC is a robust laboratory measurement score capable of determining even clinically early cases of necrotizing fasciitis ${ }^{22}$. Using logistic regression analysis of independent variables from 89 cases of necrotizing fasciitis factors were identified to be independent predictors. Of the cohort of 89 patients in one study only $13(14.6 \%)$ patients had a diagnosis or suspicion of necrotizing fasciitis on admission ${ }^{23}$. In our study it was found that LRINEC score in majority of the cases ( $56.5 \%$ ) showed a suspicious score of 06-08 whereas in about $10.1 \%$ patients, result was specific $(\geq 08)$. Therefore a majority of cases were therefore missed initially, resulting in delayed operative debridement.

According to Wong et al, the biochemical and hematologic changes in necrotizing fasciitis develop early in the evolution of the disease and the LRINEC score can stratify patients into high and moderate risk categories even when the clinical picture is still equivocal ${ }^{24}$.

In a large retrospective study of 68 patients, Corcoran et al..$^{25}$ described significant differences between non-survivors and survivors on admission laboratory parameters. Non survivors had high serum creatinine and lactate, and low serum calcium.

$E$. coli was found to be the most frequently associated micro-organisms which was discovered in approximately $39.1 \%$ of all cases of our study . S. aureus, Staphylococcus pyogenes, Enterococci species, Pseudomonas species and anaerobic organisms were recorded to be associated with $17.4 \%, 27.5 \%, 21.7 \%, 10.1 \%$ and $20.3 \%$ cases respectively .

In one study ${ }^{26}, 50 \%$ samples culture had no growth and $50 \%$ showed some growth of micro organism. $40 \%$ growth were mono microbial and $60 \%$ were poly microbial. Of all the cultures, $80 \%$ were aerobic, $6.6 \%$ anaerobic and $13.3 \%$ mixed. The most common organism isolated was Pseudomonas aeruginosa (33\%) followed by S. aureus (20\%) and Klebsiella $(13.3 \%)$ in poly microbial culture. Beta-hemolytic Streptococcus and E. coli were found to be the important cause of mono microbial infection in that study.

In their experience of 38 patients Hejase et $\mathrm{al}^{27}$ found that $90 \%$ of the patients grew polymicrobial organisms, including gram-positive and gram -negative rods and gram-positive cocci. The main strains grown were Staphylococcus aureus, $\beta$-hemolytic Streptococcus, Pseudomonas sp., E. coli and Klebsiella $s p^{27}$. In $5 \%$ of their cases no growth was reported. Korkut et al ${ }^{28}$ had a $64 \%$ positive culture rate of the 36 patients in their case series who had cultures sent during their initial debridement, and the leading mircro-organism was Escherichia coli $^{28}$. In their review of 70 patients with Fournier's gangrene Ersay et $\mathrm{a}^{29}$ found that the most frequent bacterial organisms cultured from the wounds were Escherichia coli (40.0\%), Bacteroides spp. (38.6\%), Streptococcus spp. (37.1\%), Enterococcus spp. (27.1\%), Staphylococcus spp. (25.7\%), Pseudomonas spp. (24.3\%), 
Klebsiella pneumoniae (20.0\%), and Proteus spp. (18.6\%). The bacterial organisms cultured from wound however were not independent predictors of outcome ${ }^{29}$. Kuo et al cultured a variety of organisms in their series of 44 patients in northern Taiwan $^{30}$. These were cultured from necrotic tissue or pus during surgery or at the bedside. Only 1 organism was identified in 13 patients whilst culture results in 28 patients demonstrated polymicrobial infection. In 3 patients wound cultures were negative. The most commonly isolated organisms from wound were Escherichia coli in 26 patients, Bacteroides fragilis in 17 patients, Klebsiella pneumoniae in 16 patients, Enterococcus spp. in 14 patients and Proteus mirabilis in 10 patients. Similar to the case series by Ersay et $\mathrm{al}^{29}$, mortality was not related to the specific isolated organism.

In their review of 43 reconstructive patients Ferreira et al had a positive culture from 35 of the 43 patients, with $29(82.9 \%)$ of these being polymicrobial ${ }^{30}$. The most common organisms isolated were Staphylococcus aureus (21 patients), Escherichia coli and Pseudomonas aeruginosa (11 patients).

In their review article on Fournier's gangrene Thwaini et $\mathrm{al}^{31}$ found that cultures from the wounds commonly show poly microbial infections by aerobes and anaerobes, which included coliforms, klebsiella, streptococci, staphylococci, Clostridia, Bacteroides and Cornybacteria. On average, at least three organisms were found to grow from each diagnosed patient ${ }^{31}$.

Along with the above organisms mentioned there have been cases reported of Fournier's gangrene caused by unusual organisms such as Clostridium perfringens and Clostridium $\operatorname{tetani}^{32}$.

\section{Conclusion:}

In our study on Fournier's gangrene, E coli was the most predominant organism obtained from culture studies . There were significant number of systemic complications. However mortality was fairly low. Poly microbial infection (Type I NF) was significantly high. Microbiological positivity pattern in our study was unique and positivity pattern varied among different studies internationally.

\section{References:}

1. Patankar SP, Lalwani SK. Fournier's gangrene. J Indian Paediatr 2004;41:511.

2. Kumar P, Clarke M, eds. Clinical Medicine. 5th ed. Edinburgh: WB Saunders, 2002:66-7.

3. McLatchie GR, Leaper DJ, eds. Oxford Handbook of Clinical Surgery. 2nd ed. Oxford UK: Oxford University Press, 2003:53,890.

4. Pawlowski W, Wronski M, Krasnodebski IW. Fournier's gangrene. Pol Merkuriusz Lek 2004; 17(97):85-7.

5. Yeniyol CO, Suelozogen T, Arslan M, Ayder RA. Fournier's gangrene: Experience with 25 patients and the use of Fournier's gangrene severity index score. Urology 2004;64(2):218-22.
6. Muqim R. Necrotising fasciitis: management and outcome. J Coll Physicians Surg Pak 2003;13(12):711- 4.

7. Surjushe A, Vasani R, Thakre M, Saple DG. Necrotizing fasciitis in an HIV-infected patient. Indian J Dermatol Venereol Leprol 2008;74:268-70.

8. Wong $\mathrm{CH}$, Wang YS. The diagnosis of necrotizing fasciitis. Curr Opin Infect Dis 2005;18:101-6.

9. Tang WM, Ho PL, Fung KK, Yuen KY, Leong JC. Necrotising fasciitis of a limb. J Bone Joint Surg Br 2001;83:709-14.

10. Descamps V, Aitken J, Lee MG. Hippocrates on necrotizing fasciitis. Lancet 1994;344:556.

11. Puvanendran R, Huey JC, Pasupathy S. Necrotizing fasciitis. Can Fam Physician 2009;55:981-7.

12. Anuradha DE, Biswas J, Saraswathi K, Gogate A. Microbiological features of necrotizing fasciitis. Indian $\mathrm{J}$ Med Microbiol 1999;17:18-21.

13. Sudarsky LA, Laschinger JC, Coppa GF, Spencer FC. Improved results from a standardized approach in treating patients with necrotizing fasciitis. Ann Surg 1987;206:661-5.

14. Miller LC, Perdreau-Remington F, Rieg G, Mehdi S, Perlroth J, Bayer AS, et al. Necrotizing fasciitis caused by community associated methicillin-resistant Staphyococcus aureus in Los Angeles. N Eng J Med 2005;352:1445-53.

15. Anaya DA, Dellinger EP. Necrotizing soft-tissue infection: Diagnosis and management. Clin Infect Dis 2007;44:705-10.

16. McHenry CR, Piotrowski JJ, Petrinic D, Malangoni MA. Determinants of mortality for necrotizing soft-tissue infections. Ann Surg 1995;221:558-63.

17. Wong CH, Chang HC, Pasupathy S, Khin LW, Tan JL, Low CO. Necrotizing fasciitis: Clinical presentation, microbiology, and determinants of mortality. J Bone Joint Surg Am 2003;85-A:1454-60.

18. Anaya DA, McMahon K, Nathens AB, Sullivan SR, Foy H, Bulger E. Predictors of mortality and limb loss in necrotizing soft tissue infections. Arch Surg 2005;140:151-7.

19. Sentochnik DE. Deep soft-tissue infections in diabetic patients. Infect Dis Clin North Am 1995;9:53-64.

20. Pawłowski W, Wroński M, and Krasnodębski WI, "Fournier's gangrene," Polski Merkuriusz Lekarski,2004. vol. 16, no. 97, pp. $85-87$.

21. Wong $\mathrm{CH}$, Wang YS. The diagnosis of necrotizing fasciitis. Curr Opin Infect Dis 2005;18:101-6.

22. Wong CH, Khin LW, Heng KS, Tan KC, Low CO, "The LRINEC (Laboratory Risk Indicator for Necrotizing Fasciitis) score: a tool for distinguishing necrotizing fasciitis from other soft tissue infections," Crit Care Med 2004, vol. 32, no. 7, pp. 1535-1541.

23. Ersay A, Yilmaz G, Akgun Y, and Celik Y, "Factors affecting mortality of Fournier's gangrene: review of 70 patients," ANZ Journal of Surgery 2007, vol. 77; 43-48.

24. Thwaini A, Khan A, Malik A et al., "Fournier's gangrene and its emergency management," Postgraduate Medical Journal 2006, vol. 82, no. 970: 516-519.

25. Corcoran AT, Smaldone MC, Gibbons EP, Walsh TJ, and Davies BJ, "Validation of the Fournier's gangrene severity index in a large contemporary series," Journal of Urology 2008, vol. 180; 944-948.

26. Tang WM, Ho PL, Fung KK, Yuen KY, Leong JC. Necrotising fasciitis of a limb. J Bone Joint Surg Br 2001;83:709-14. 
Bangladesh Crit Care J March 2017; 5 (1): 28-32

27. Hejase, MJ, Simonin, JE, Bihrle, Coogan, C, Genital Fournier's gangrene: experience with 38 patients. Urology 1996, 47, 734-739.

28. Korkut M, Dayangaá M, Akg,NE, Yeniay L, Erdo AN, Outcome analysis in patients with Fournierís gangrene. Diseases of the Colon \& Rectum, 46, 649-652, 2003.

29. Ersay A, Yilmaz G, Akgun Y, Celik Y, Factors affecting mortality of Fournierís gangrene: review of 70 patients. ANZ journal of surgery 2007, 77, 43-48.
30. Kuo C, Wang W, Lee C, Liu C, Tseng H, Fournier's gangrene: ten-year experience in a medical center in northern Taiwan. $\mathrm{J}$ Microbiol Immunol Infect 2007, 40, 500-506.

31. Thwaini A, Khan A, Malik A, Cherian J, Barua J, Shergill I, Mammen K, Fournierís gangrene and its emergency management. Postgraduate medical journal,2006. 82(970); 516-9.

32. Omotoso A, Aderibigbe A, Fournierís gangrene complicated by tetanus: case report. Orient J Med,1990 2: 207-8. 